\title{
Population, Society, and Environment on the Verge of the 21st Century: An Overview
}

\author{
JUVAL PORTUGALI* \\ Department of Geography, Head of The Graduate Program for Environment and Society, \\ Tel Aviv University, Tel Aviv, Israel \\ (Received 1 March 1999)
}

\begin{abstract}
Keywords: Synergetics, Self-organization, Population, Family planning, Environment, Carrying capacity, Environmental ethics, Environmental policy
\end{abstract}

Population was a hot subject in public debate and scientific discourses of 19th century Europe. Following Malthus' provocative essay on the principle of population, it became a central issue in social theory as well as a source of inspiration to Darwin's theory of evolution. Contrary to Malthus' pessimistic view, Herbert Spencer suggested that the tension between population growth and environmental resources is the major force pushing society toward progress, whereas Karl Marx considered this tension to be false (consciousness), suggesting that the real problem is an uneven distribution in a Capitalist society. For Darwin, as he notes in his writings, Malthus ideas were a source of inspiration to the mechanism of natural/environmental selection.

Since then the issue of population has attracted scientists in many disciplinary domains: social theorists, anthropologists, life-scientists, geographers, environmentalists, urban and regional planners, system analysts, and of course, demographers, social workers, family planners and others. The study of population from so many aspects enriched our knowledge and understanding enormously: we have today much better and detailed data on population than ever before, we understand much better the inter-relationships between economic, cultural and biological forces which affect population. Moreover, never before have we been so well equipped with high speed computers with highly sophisticated programs, which enable us to manipulate data, run simulations and suggest demographic forecasts. And yet, despite all the progress, the basic dilemmas are still with us: today, on the verge of the 21 st century, "the population bomb" is still a threat, some say more menacing than ever before and on a larger, world wide scale; and the old controversy over what constitutes the population question - a natural phenomenon of population-environment tension,

*Tel.: +972(3)640-8661. Fax: +972(3)640-6243. E-mail: juval@)post.tau.ac.il. 
or a socio-political phenomenon of uneven distribution of resources - is still as hot today as it was more than a century ago.

Can we say today, on the verge of the 21st century, more than Malthus, Spencer, Marx, Condorset, Darwin and others in the 19th century? Are we going in circles? or is it that the nature of the issue is such that there are no final and finite answers? And if so, can we ask today the very same questions in a more articulated way than the founding fathers of social theory and the life sciences?

This special issue comes to explore these dilemas from four different perspectives: from the perspective of the theory of self-organization, from the perspective of medicine and family planning, in relation to economics and the notion of carrying capacity, and with respect to environmental ethics and politics.

\section{PART ONE: SYNERGETICS, SELF- ORGANIZATION AND POPULATION}

As is well recorded in the literature, the notion of "progress" which dominated social theory, and the notion of "evolution" which dominated the life sciences, were from the start intimately interrelated - mainly by their implied view of an upward-tending process of change. This was not the case, however, with the "hard" sciences which were dominated by the Newtonian world view of a mechanistic universe and by classical thermodynamics with its downward-tending process of change leading to maximum entropy. The various notions of self-organization which are emerging in recent decades seem to change this inconsistency. They suggest that progress and evolution are properties of the material world too, that is to say, these new theories have found in the domain of matter properties hithertoo assigned to the life, social and human domains, with the implications (a) that the questions of evolution and progress have now become questions of the hard sciences and consequently of science as a whole, and (b) that for the first time we are now in a position to examine a question such as the relations between population, environment and society, as a question of science as a whole - a phenomenon or a common ground around which a genuine discourse between people from the hard and soft sciences can develop. The papers that form Part 1 are related to the various facets of the theory of self-organization. While all writers share the conviction that the population-environment-society triangle is a highly complex self-organizing system, some of them, in particular Allen, refer to the issue by emphasing general theoretical aspects, whereas others, like Weidlich, Batty and Xie, Meron, Benenson, and Omer, by focusing on population issues associated with cities and urbanizm. Another distinction concerns methodology. While all writers are using simulation models as their central methodology to study complexity and self-organization, some of the models - those of Allen, Weidlich and Meron are constructed by means of differential equations, whereas the other - the models developed by Batty and Xie, Benenson, and Omer, on the basis of Cellular Automata.

If Part 1 attempts to introduce some new approaches and discourses to the discussion, then Parts 2-4, are devoted to three issues which stand at the core of the population-environment-society debate: contraception and family planning, environmental carrying capacity, and environmental ethics and polity.

\section{PART TWO: CONTRACEPTIONS AND FAMILY PLANNING}

Contraceptions and family planning are among the most direct and immediate responses that science and technology can suggest to the issue of population growth. In the final analysis the various population processes that our models analyse and often predict, will depend to a large extent on the advance made in the technology of contraceptions and its 
application to family planning. The papers by Tarnesby and Caspi present the state of the art in this domain and indicate future prospects and trends. As the papers emphasis, however, contraceptions and family planning are not purely technical, and both have strong cultural and social dimensions. The challenge here is, thus, not only technological innovation and improvement, but innovation and improvement which will be culturally and socially accepted and effective.

\section{PART THREE: ENVIRONMENTAL CARRYING CAPACITY}

Environmental Carrying Capacity is the modern term to the Malthusian notion that there is a limit to human kind's ability to exploite the environment. The term is important and interesting. Important, since it refers to some of the most acute problems of modern society and its relation to the environment (which also from the titles of Ross and Amir papers): "will there be enough food on the table?", or "is it possible to eat the cake and have it?". Carrying capacity is also an interesting term because, on the one hand, it is a straightforward term which can immediately and intuitively be grasped. But on the other hand, when you get closer and try to formally define and measure it, you run into problems: the notion is intimately related to culture, beliefs and religions, to economics, social structure and politics. That is to say, to human dimensions which, while identifiable, are very subtle and thus not definable nor measurable. Both the important and the interesting aspects of carrying capacity are examined in Part 3.

\section{PART FOUR: ENVIRONMENTAL ETHICS AND POLITICS}

Malthus, Spencer, Marx, Darwin and others are among the founding fathers of not only modern science, but also of modernism as the dominant world view of Western Society (or of the 1st world as it is often called to distinguish it from the $3 \mathrm{rd}$ world of developing countries). From this perspective it is not surprising that a concern to population growth and its effects on the environment are becoming more and more important components of the Western, 1st world culture. Many environmental problems are global and do not recognize the 1st vs. 3rd world division, and thus environmentalists in the West, who are concerned with 3rd world population-environmental problems, work hard to transmit their Western 1st world view to the 3rd world. Is this an inevitable, value-free and neutral process, or is it a new form of imperialism liberal imperialism - which is more subtle and civilized, but nevertheless very political effective and even oppressive?

Many environmental problems are by their nature global in scale and thus disregard political boundaries and nation state. That is to say, the world's socio-spatial order of a humanity divided into nations, national territories and their governments. A global environmental world-view thus conflicts with, and in some cases challenges, the nationalistic world view which dominates modern society. Furthermore, in some cases solving a global population-environment problem might threaten the quality of the environment at a local-national scale. These issues are discussed in Part 4 in the papers of Curtin, Norton and Nash. 


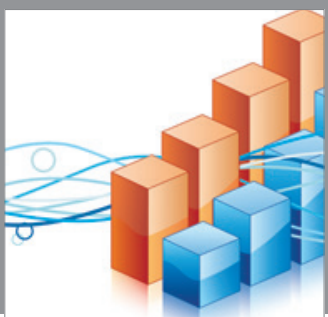

Advances in

Operations Research

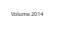

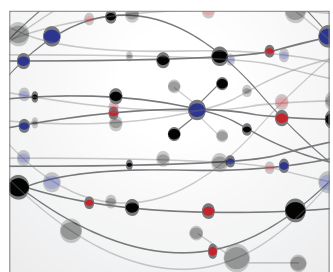

\section{The Scientific} World Journal
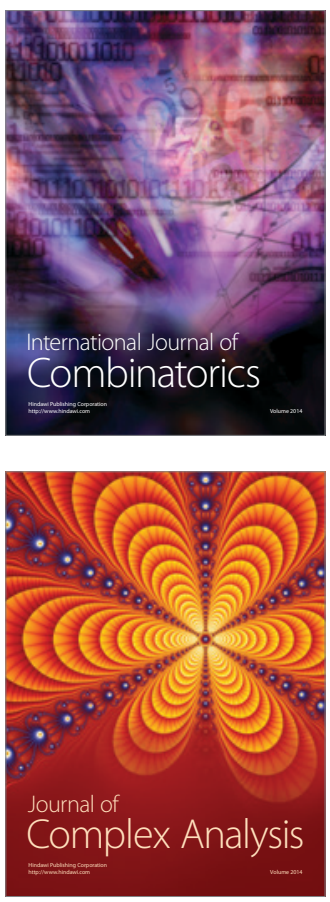

International Journal of

Mathematics and

Mathematical

Sciences
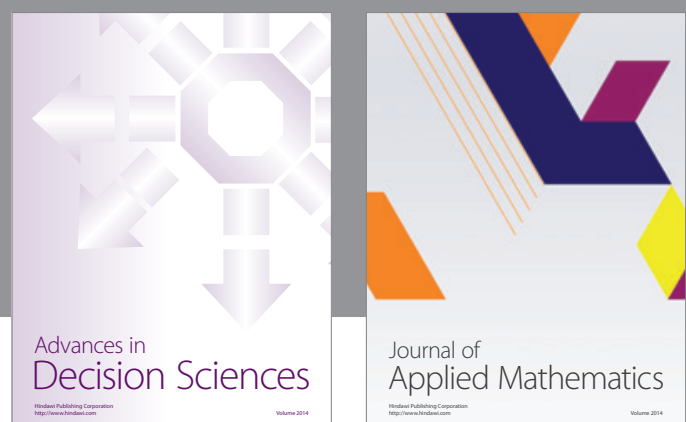

Journal of

Applied Mathematics
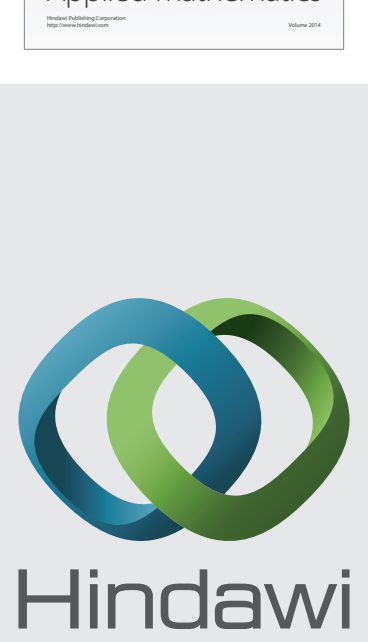

Submit your manuscripts at http://www.hindawi.com
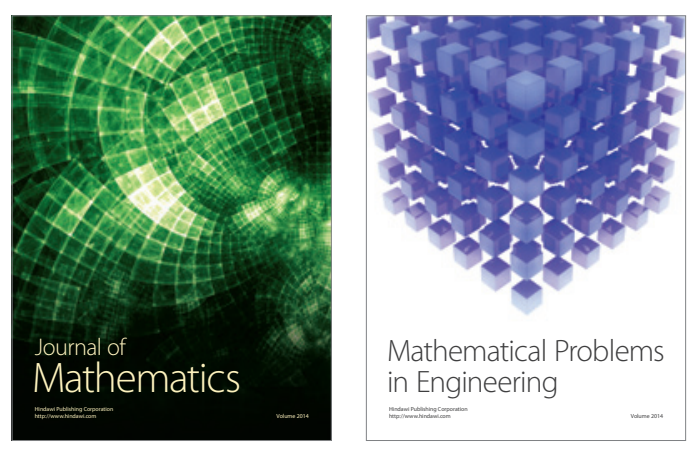

Mathematical Problems in Engineering
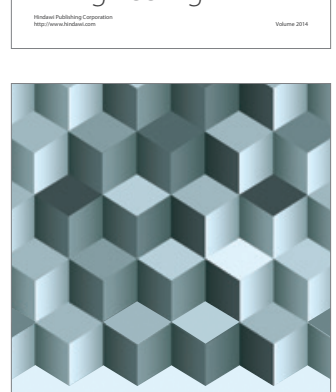

Journal of

Function Spaces
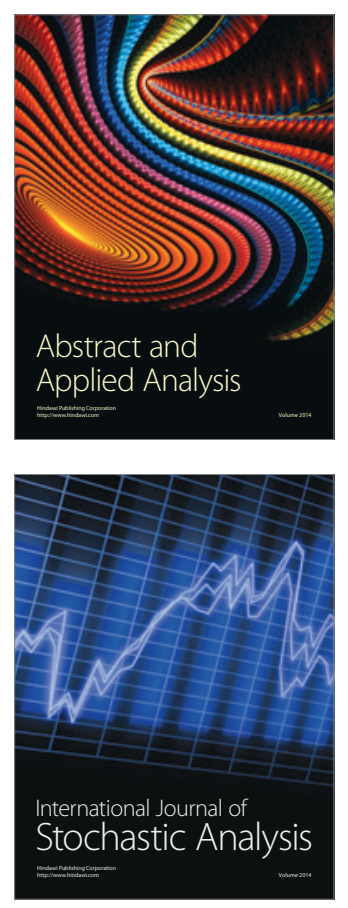

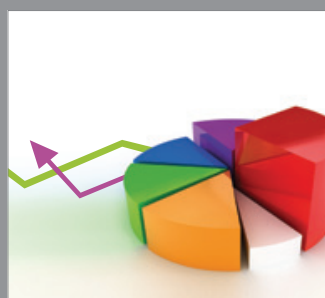

ournal of

Probability and Statistics

Promensencen
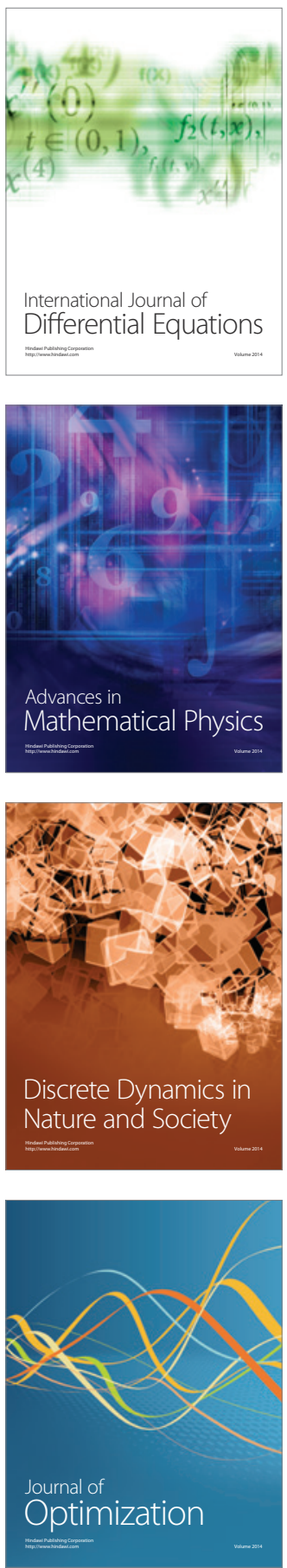